\title{
Oral Surgery during Covid-19 Epidemic - Albanian Experience for Patient Management Attending Emergency Dental Services
}

\author{
Merita Bardhoshi $^{1 *}$, Edit Xhajanka ${ }^{2}$, Eriselda Malushi ${ }^{3}$, Dea Bardhoshi ${ }^{4}$ \\ ${ }^{1}$ Department of Oro-maxillofacial Surgery, Faculty of Dental Medicine, Medical University of Tirana, Tirana, \\ Albania \\ ${ }^{2}$ Department of Prosthodontic, Faculty of Dental Medicine, Medical University of Tirana, Tirana, Albania \\ ${ }^{3}$ Oral Division, University Dental Clinic, Medical University of Tirana, Tirana, Albania \\ ${ }^{4}$ University of California, San Francisco, USA
}

*Corresponding Author: Merita Bardhoshi, Department of Oro-maxillofacial Surgery, Faculty of Dental Medicine, Medical University of Tirana, Tirana, Albania.

\begin{abstract}
Introduction: The first two cases of COVID-19 in Albania were confirmed on 8 March 2020 by the Institute of Public Health in Tirana. Strict containment measures were adopted by the Government, during the lockdown and a re-organisation of dental care services in Albania was implemented. The Ministry of Health and Social Protection in Albania decided to close all dental private clinics to decrease the risk of infection, while all dental treatments were performed by the specialised dental professionals of the public University Dental Clinic in Tirana. The aim of this study was to describe the characteristics of patients who accessed the Department of Oral Surgery of the University Dental Clinic and to report the preventive measures adopted during the lockdown period of 19 March to 18 May 2020.
\end{abstract}

Material and Method: Medical charts from individuals attending the Department of Oral Surgery of the University Dental Clinic in Albania were analyzed. This was a cross-sectional study, conducted in Tirana. For minimizing risk for infection to patients and dental healthcare personnel, several preventive strategies were adopted. Categorical variables were reported as counts and percentages, and differences between groups (men vs women) were evaluated with the chi-square test or Fisher's Exact test when appropriate. All analyses were performed using SPSS v. 26.0 (IBM, NY, USA).

Results: The study comprised 209 patients (90 females and 119 males), aged from 1 to 85 years old, presenting different dental and oral pathologies. According to the recommendations of the Ministry of Health and Social Protection in Albania, to avoid the spread of infection, University Dental Clinic took the measurements for a safety treatment for the patients and operators. Precautions, taken for operator, patient and environment are described. Inflammatory pathologies were the common reasons for patients visits in our Oral Surgery Department in this study because of periapical periodontitis, periodontal disease, dental abscess inflammatory pathologies of sinus and salivary gland, followed by dental trauma, bleeding and haemorrhagic epulis working in special conditions. A list of preventive actions adopted in Albania for dental practitioners during the COVID-19 emergency are described.

Conclusion: Based on the results of this study, we provided preventive measurements in the management of patients, operators and the environment. Recommendation proposed, could help to improve the quality of assistance for patients with dental disorders and reduce the risk of infection in dental setting during the COVID-19 pandemic.

Keywords: SARS-CoV-2; dental setting; Triage

\section{INTRODUCTION}

In December 2019, in Wuhan City, a severe form of pneumonia of unknown cause was detected [1]. This pneumonia infection has rapidly spread from Wuhan to other countries. Chinese researchers have quickly discovered and isolated a novel Coronavirus (SARS-CoV2) and announced a name for a new coronavirus disease called, by the World Health Organization (WHO), Coronavirus Disease 19 (COVID-19) [2] and increased the assessment of the risk of spread to "very high" [3]. After 
mitigating the epidemic in China, Italy became one of the most COVID-19 affected countries worldwide [4]. Due to its political, geographic and cultural similarities, Italy is one of the main economic partners of Albania. In fact, data show that the first index case identification in Albania was travel-related with Italy on 9th March 2020. The first two cases of COVID -19 in Albania were confirmed on 8 March 2020 by the Institute of Public Health in Tirana. After the first case identification, the number of cases in Albania is continually rising reaching the total number of 6.676 confirmed cases of COVID-19 with 205 deaths and overall Case Fatality Ratio (CFR) of 3\% by 13 August 2020, ranking 74th country in the world in terms of the number of confirmed cases [5]. On 10th March 2020, schools and Universities were closed and a total lockdown was put in place two days after. Strict containment measures adopted by the Government established the limitation of people circulating outside their homes, social distancing, the closure of almost all commercial activities, remote working and home schooling using online Platforms [6]. COVID-19 has had a significant impact on dentistry in Albania due to the perceived risks associated with infection control and timely and early management of acute dental emergencies is important to avert patients from accident and emergency services and to avoid hospital admissions. Reorganisation of dental care services were performed in dental practices. Albania is a developing country undergoing many political and economic changes in an effort to become a member of the European Union. In Albania, Dental care is private, with the exception of emergency dental services and services provided in school to children up to age 18. Both of these public services are free. During lockdown in Albania, the Ministry of Health and Social Protection decided to close all dental private clinics to decrease the risk of infection and there was a suspension of routine dental care in the private practice. All dental treatments were performed by the specialised dental professionals of the public University Dental Clinic in Tirana that had remained open during the lockdown period from 19 March to 11 May. Due to the characteristics of dental setting, dental practitioners are the most exposed workers to the risk of being affected by COVID19. It has been widely documented in the literature that common human to human transmission routes of SARS-CoV-2 include droplet (diameter $\geq 5 \mu \mathrm{m}$ ) and aerosol (diameter
$<=5 \mu \mathrm{m})$ inhalation generated from coughs and sneezes of infected patients, as well as direct contact with oral, nasal and eye mucous membranes [7]. In addition, studies have shown that SARS-CoV-2 can be transmitted through saliva $[8,9,10]$. The dental practitioners routinely perform several aerosol-generating procedures due to the use of different tools, like dental high-speed turbine, spray handpiece, or piezoelectric scaler. These instruments largely increase the aerosol produced inside the work environment, thus exposing both clinicians and patients to the risk of infection [11]. Based on these considerations, all dentistry operators must always be diligent in protecting against the spread of viral disease, as well as note the importance of providing clear and easy guidelines to manage patients and make dental practice safe from any risk $[12,13]$. The aim of this study was to examine the effect of COVID19 outbreak on the Albanian dental setting and how this situation was managed by the Department of Oral Surgery of the University Dental Clinic in Tirana. In particular, the objectives were two-fold: to describe the characteristics of patients who accessed the Department of Oral Surgery of the University Dental Clinic and to report the preventive measures adopted.

\section{Materials AND Methods}

Medical charts from individuals attending the Department of Oral Surgery of the University Dental Clinic in Albania were analyzed. The Department is responsible for the dental care management of Tirana area, the main city and capital of Albania. Approximately a quarter of the country's population ( 900.000 citizens) lives in Tirana as it is the most important cultural, social and economic city of the country. The design of the study was cross-sectional and involved the participation of patients who accessed to the Department of Oral Surgery from 19 March to 18 May 2020. Main outcomes patients' measures were demographics (i.e. age, gender), health status (prevalence of comorbidities), dental, oral conditions and treatment procedures conducted. Ethical approval and written informed consent was obtained from all subjects before the study.

\subsection{Statistical Analysis}

Categorical variables were reported as counts and percentages, and differences between groups (men vs. women) were evaluated with the chi-square test or Fisher's Exact test when 
appropriate. A P-value $<0.05$ was considered as statistically significant. All analyses were performed using SPSS v. 26.0 (IBM, NY, USA)

\subsection{Preventive Strategies Adopted}

For minimizing risk for infection to patients and dental healthcare personnel, several preventive strategies were adopted.

Measures for COVID-19 management adopted in Albania are divided in groups:

\subsubsection{Operator Management}

All operators followed the same preventive rules:

\subsubsection{Use of Appropriate Personal Protective Equipment (PPE) For Dental Practitioners}

SARSCoV-2 transmission predominantly occurs through airborne droplets. In this sense, the use of protective equipment, including gloves, masks, protective outerwear, protective surgical glasses, and shields, is strongly recommended to protect the eyes, oral, and nasal mucosa Application of face masks (filtering face piece level 2 or 3), shields, surgical glasses, longsleeved water-resistant gown, surgical cap, shoe cover were used.

\subsubsection{Controlling and Maintaining Physical Distancing}

Use of Plexiglas barriers at tills and counters as an additional level of protection for staff; floor markings inside the retail store were used of dentist operator. Hand hygiene is a critical measure for reducing SARS-CoV-2 transmission. It is crucial to perform thorough hand washing when coming into contact with patients and non disinfected surfaces or equipment; it is recommended to avoid touching eyes, mouth, and nose without having hands carefully washed. It is also advised to wash hands for at least $60 \mathrm{~s}$, to use hand sanitizer with alcohol-based content of over $60 \%$ prior to wearing gloves, before and after each patient treatment.

\subsubsection{Patient Management}

Patient triage screening was the first step to identify suspected cases of COVID-2019 to avoid extended contact with a potentially infected patient altogether. Performing triage to investigate current health status and/or the presence of risk factors for COVID-19 development is strongly suggested when receiving patients. Triage was performed when patients entered the clinic. To each visit, we checked the temperature with a touchless forehead thermometer as well as the oxygen level and pulse rate with an oximeter. Patients were screened using a prepared questionnaire. The set of questions aimed at investigating the risk of exposure to SARS-CoV-2 are reported in Table 1.

Table1. Triage questionnaire to evaluate patients' potential risk of SARS-CoV-2 infection

Have you had fever, cough, cold, breathing difficulties, muscle pain, loss of taste and smell, headache in the last 21 days?

Have you had contacts with infected individuals in the last 21 days?

Have you been in a previously quarantined area?

Have you had contact with individuals coming from a quarantined area?

- One clinic administrator responsible to properly identify for symptoms of COVID-19 among incoming patients. If symptoms are presented, the individual is prohibited from participating in treatment and the emergency service was notified. The physicians used clinical judgment to determine whether a patient who was presented for care has symptoms of in influenza like illness or symptoms compatible with COVID-19 to make a decision regarding testing and to coordinate testing through public health laboratories. A hub COVID Centre situated at Oro -Maxillofacial Department at the University Hospital Centre "Mother Theresa" in Tirana was identified to manage the patients with COVID 19.

- One nurse responsible for the temperature measurement of every person presented in the dental clinic. Individuals with a fever of above 37.5 degrees Celsius was not allowed to enter the dental clinic.

- One dental clinician responsible for the management of the patient.

\subsubsection{Environment Management}

Precautions were taken also for the environment control. Everything that came into contact with the patient (button, counters, chairs) has been disinfected using a $70 \%$ ethyl alcohol solution. Waiting room was well ventilated and the toilets were equipped with soap and alcoholic gel solutions for hand disinfection as well as disposable wipes. 
Oral Surgery during Covid-19 Epidemic - Albanian Experience for Patient Management Attending Emergency Dental Services

Operating area and all surfaces were disinfected using $70 \%$ ethyl alcohol solution before and after each treatment and were adequately ventilated.

Considering that aerosol-generating procedures represent the critical moment in the dental practice in the COVID-19, limitation of aerosolproducing procedures and high levels of suction was applied to minimize and to reduce as much as possible the production of aerosol/droplets during the procedure. Use of hand pieces were avoided when possible.

\subsubsection{Treatment Classification}

During pandemic diffusion of COVID-19, dental activities must be limited to the treatments that cannot be postponed and dental practitioners should perform only emergency treatments. Indeed, treatment should be effective and pragmatic, aimed at just the resolution of the emergency.

The treatments were classified in "urgent" and "non-urgent" categories, as following:

2.2.4.1. "Urgent" treatments were considered those that required intervention within 24 hours and immediate attention to relieve. They included:

\section{- $\quad$ Uncontrolled bleeding}

- $\quad$ Soft tissue infection with intraand extra-oral swelling patient's airways, abscess and localized bacterial infection

inflammation

- $\quad$ Pericoronitis

- $\quad$ Surgical post-operative osteitis

- Dental trauma

- $\quad$ Biopsy of abnormal tissue.

2.2.4.2. Non "urgent" treatments were considered those that required to be postponed and scheduled by the dentist. They included:

\section{- $\quad$ Asymptomatic carious lesion \\ - $\quad$ Routine dental cleaning and preventive therapies \\ Orthodontic treatment \\ Prosthodontic treatment}

\section{RESULTS}

The study included 209 patients (90 females; $43.1 \%$ and 119 males; $56.9 \%$ ), with a mean age of 41.7 years. Demographic and health status characteristics of patients are reported in Table 2.

Table2. Demographic and health status characteristics of 209 patients

\begin{tabular}{|c|c|c|c|c|c|}
\hline & & n & $\%$ & CI 95.0\% & p-value \\
\hline \multirow[t]{2}{*}{ Gender } & Female & 90 & $43.1 \%$ & {$[36.5: 49.8]$} & \multirow[t]{2}{*}{$\mathrm{p}=0.02$} \\
\hline & Male & 119 & $56.9 \%$ & $\begin{array}{c}50.2- \\
63.5]\end{array}$ & \\
\hline \multirow[t]{5}{*}{ Age } & $0-19$ & 19 & $9.1 \%$ & [5.8-13.6] & \multirow{5}{*}{$\mathrm{p}=0.025$} \\
\hline & $20-39$ & 79 & $37.8 \%$ & $\begin{array}{c}{[31.4-} \\
44.5]\end{array}$ & \\
\hline & $40-59$ & 69 & $33.0 \%$ & $\begin{array}{c}{[26.9-} \\
39.6]\end{array}$ & \\
\hline & $60-79$ & 41 & $19.6 \%$ & $\begin{array}{c}14.7- \\
25.4]\end{array}$ & \\
\hline & $80+$ & 1 & $0.5 \%$ & {$[0.1-2.2]$} & \\
\hline \multirow{2}{*}{$\begin{array}{c}\text { Good } \\
\text { Health } \\
\text { status }\end{array}$} & Yes & 155 & $74.2 \%$ & [67.9-79] & \multirow[b]{2}{*}{$\mathrm{p}=0.03$} \\
\hline & No & 54 & $25.8 \%$ & $\begin{array}{l}{[20.3-} \\
32.1]\end{array}$ & \\
\hline
\end{tabular}

The children age group (0-19 years) represented $8 \%$ of the study population; the 20-39 age groups represented 38\%, 40-59 comprised 33\%, 60-79 represented $20 \%$ and $80+$ consisted in $1 \%$ of the population study.

A gender disparity in the accessibility of patients to the department has been highlighted with a predominate rate of male individuals (57\% male versus $43 \%$ female, as reported in Table 2). These differences were statistically significant $(\mathrm{P}=0,02)$.

The clinical characteristics of individuals are reported in Table 3.

Table3. Clinical characteristics of individuals

\begin{tabular}{|c|c|c|c|c|c|c|c|c|}
\hline \multirow{2}{*}{\begin{tabular}{|c|}
$\begin{array}{c}\text { Disease } \\
\text { name }\end{array}$ \\
\end{tabular}} & \multicolumn{2}{|c|}{ Female } & \multicolumn{2}{|r|}{ Male } & \multicolumn{2}{|r|}{ Total } & \multirow[b]{2}{*}{\begin{tabular}{|c|} 
CI \\
$95.0 \%$ \\
\end{tabular}} & \multirow{2}{*}{\begin{tabular}{|c|}
$\mathbf{P}$ \\
value \\
\end{tabular}} \\
\hline & $\mathbf{n}$ & $\%$ & $\mathbf{n}$ & $\%$ & $\mathbf{n}$ & $\%$ & & \\
\hline Diabetes & 1 & $3.6 \%$ & 2 & $7.7 \%$ & 3 & $5.6 \%$ & \begin{tabular}{|l|}
{$[1.6-$} \\
$14.1]$
\end{tabular} & $\begin{array}{c}P=0.0 \\
69\end{array}$ \\
\hline $\begin{array}{c}\text { Hypertensi } \\
\text { on arterial } \\
\end{array}$ & 19 & $67.9 \%$ & 11 & $42.3 \%$ & 30 & $55.6 \%$ & \begin{tabular}{|c|}
$642.3-$ \\
$68.2]$ \\
\end{tabular} & \\
\hline $\begin{array}{l}\text { Hypertensi } \\
\text { on arterial } \\
\text { \& Diabetes }\end{array}$ & 3 & $10.7 \%$ & 2 & $7.7 \%$ & 5 & $9.3 \%$ & $\begin{array}{l}3.6- \\
19.1]\end{array}$ & \\
\hline \begin{tabular}{|c|} 
Coagulopat \\
hy
\end{tabular} & 3 & $10.7 \%$ & 4 & $15.4 \%$ & 7 & $13.0 \%$ & \begin{tabular}{|l|}
{$[6.0-$} \\
$23.8]$
\end{tabular} & \\
\hline $\begin{array}{c}\text { Cardiovasc } \\
\text { ular } \\
\text { diseases }\end{array}$ & $\mathbf{0}$ & $0.0 \%$ & 1 & $3.8 \%$ & 1 & $1.9 \%$ & $\begin{array}{c}0.2- \\
8.3]\end{array}$ & \\
\hline Epilepsy & 1 & $3.6 \%$ & 3 & $11.5 \%$ & 4 & $7.4 \%$ & $\begin{array}{l}2.6- \\
16.7]\end{array}$ & \\
\hline \begin{tabular}{|c|}
$\begin{array}{c}\text { Pulmonary } \\
\text { diseases }\end{array}$ \\
\end{tabular} & $\mathbf{0}$ & $0.0 \%$ & 1 & $3.8 \%$ & 1 & $1.9 \%$ & \begin{tabular}{c|}
{$[0.2-$} \\
$8.3]$
\end{tabular} & \\
\hline $\begin{array}{l}\text { Vascular } \\
\text { diseases }\end{array}$ & 1 & $3.6 \%$ & 1 & $3.8 \%$ & 2 & $3.7 \%$ & \begin{tabular}{|l|}
{$[0.8-$} \\
$11.4]$ \\
\end{tabular} & \\
\hline Hepatitis B & $\mathbf{0}$ & $0.0 \%$ & 1 & $3.8 \%$ & 1 & $1.9 \%$ & \begin{tabular}{|l|}
{$[0.2-$} \\
$8.3]$
\end{tabular} & \\
\hline Total & 28 & $100.0 \%$ & 26 & $100.0 \%$ & 54 & $100.0 \%$ & & \\
\hline
\end{tabular}


Oral Surgery during Covid-19 Epidemic - Albanian Experience for Patient Management Attending Emergency Dental Services

The prevalence of clinical conditions among the study population was $25.8 \%$ (54/209), with a confidence interval between $20.3 \%$ and $32.1 \%$ ]. No statistically significant difference between male and female comorbidities was observed $(\mathrm{p}=0.69)$. Hypertension arterial disease were the most commonly encountered disorder $(14.3 \%)$, whereas among the patient reporting a disease $(55.6 \%)$. The table 4 reported the distribution of oral and dental pathologies among study population. Out of 209 patients, 89 (43\%) had dental abscess, 79 (37\%) periodontal inflammation, 11 (5\%) soft tissue infection, 30 others $(15 \%)$ had bleeding (1.91\%), epulis hemorrhagic $(1.91 \%)$, pericoronitis $(1.91 \%)$, acute arthritis (2.39\%), osteitis (0.95\%), sinusitis $(0.47 \%)$, and acute sialoadenitis $(1.47 \%)$. There was a statistically significant difference in the distribution of female and male patients for dental pathologies (the p-value $=$ 0.02). Compared with men, women were less likely to have developed dental pathologies.

Table4. Distribution of dental and oral pathologies

\begin{tabular}{|l|c|c|c|}
\hline $\begin{array}{l}\text { Dental and oral } \\
\text { pathologies }\end{array}$ & Male & Female & Total \\
\hline Dental Abscess & 40 & 49 & 89 \\
\hline $\begin{array}{l}\text { Periodontal } \\
\text { inflammation }\end{array}$ & 36 & 43 & 79 \\
\hline Soft tissue infection & 8 & 3 & 11 \\
\hline Dental Trauma & 3 & 4 & 7 \\
\hline Bleeding & 3 & 1 & 4 \\
\hline Epulis hemorrhagic & 1 & 3 & 4 \\
\hline Pericoronitis & 2 & 2 & 4 \\
\hline Acute arthritis & 0 & 5 & 5 \\
\hline Osteitis & 1 & 1 & 2 \\
\hline Sinusitis & 0 & 1 & 1 \\
\hline Acute sialadenitis & 2 & 1 & 3 \\
\hline
\end{tabular}

Among the 209 patients, classified as a need for urgent treatment, different modalities of treatment were used for the management of dental and oral pathologies. Results are reported in Table 5. 47 patients were excluded from the study as their dental pathologies were not considered urgent.

Table5. Modalities of treatment

\begin{tabular}{|c|c|c|}
\hline Type of treatment & n & \% \\
\hline Consultation & 42 & 20 \\
\hline Dental Extraction & 56 & 26.8 \\
\hline Draining & 12 & 5.7 \\
\hline Trepanation, analgesic & 6 & 2.87 \\
\hline Antibiotic therapy & 85 & 40.6 \\
\hline Hemostasis & 4 & 1.91 \\
\hline Laser & 4 & 1.91 \\
\hline Total & 209 & 100 \\
\hline
\end{tabular}

The principles of treatment for cases with inflammatory pathologies was to establish antibiotic therapy $(40.6 \%)$, tooth extraction (26.8\%). Drainage of tissues spaces was performed by extra and intraoral incision. Trepanation was performed for the treatment of cases with acute periapical periodontitis in order to make the drainage of pus. Diode laser $980 \mathrm{~nm}$ was used for the excision of the cases with epulis hemorrhagic. It is a safe, quick and easy to perform method with very good healing results. Haemostasis was achieved using the technique of the packing the socket with absorbable cellulose and the application of selfabsorbable sutures.

A summary of preventives measurements are described. In particular, table 6 reported a summary of the measures recommended at admission to dental service, before, during and after treatment.

Table6. Preventive actions adopted in Albania for Dental Practitioners during the COVID-19 Emergency

\begin{tabular}{|c|c|}
\hline \multicolumn{2}{|c|}{ Admission Management } \\
\hline $\begin{array}{r}\text { Patient } \\
\text { admission into } \\
\text { practise }\end{array}$ & $\begin{array}{l}\text { admission to "standby area " } \\
\text { provide adequate ventilation } \\
\text { assure social distancing measure. } \\
\text { discourage the presence of } \\
\text { accompanying people }\end{array}$ \\
\hline $\begin{array}{r}\text { Patient triage } \\
\text { screening }\end{array}$ & $\begin{array}{l}\text { use of triage questionnaire to } \\
\text { evaluate patients } \\
\text { with 'Potentional Risk of SARS - } \\
\text { CoV-2 infection }\end{array}$ \\
\hline \begin{tabular}{|l} 
Body \\
temperature \\
measurement
\end{tabular} & $\begin{array}{l}\text { Assess potential presence of fever } \\
\text { via contactless thermometer }\end{array}$ \\
\hline $\begin{array}{l}\text { Hand hygiene } \\
\text { (for patient) }\end{array}$ & $\begin{array}{l}\text { Use of hydroalcoholic solutions } \\
\text { for hand disinfections }\end{array}$ \\
\hline \multicolumn{2}{|c|}{ Before dental treatment } \\
\hline \multicolumn{2}{|c|}{\begin{tabular}{r|l} 
Environment & use of $70 \%$ ethylalcohol for the \\
disinfection & disinfection of all surfaces
\end{tabular}} \\
\hline $\begin{array}{r}\text { Patient } \\
\text { preparation }\end{array}$ & $\begin{array}{l}\text { use of disposable shoe covers } \\
\text { use for } 1 \text { minute of mouth rinse } \\
\text { with } 1 \% \text { hydrogene Peroxide }\end{array}$ \\
\hline $\begin{array}{r}\text { Clinical staff } \\
\text { hand washing }\end{array}$ & $\begin{array}{l}\text { Hand washing for at least } 60 \mathrm{~s} \text { and } \\
\text { then hand disinfecting with } 60 \% \\
\text { hydroalcoholic solution }\end{array}$ \\
\hline $\begin{array}{r}\text { Clinical staff } \\
\text { clothing }\end{array}$ & $\begin{array}{l}\text { application of face mask FFP } 2, \\
\text { face shield, gloves , cap, } \\
\text { protective waterproof clothing, } \\
\text { shoe cover }\end{array}$ \\
\hline \multicolumn{2}{|c|}{ During Dental treatment } \\
\hline Instruments & $\begin{array}{l}\text { preparation of all instruments in } \\
\text { advance }\end{array}$ \\
\hline
\end{tabular}




\begin{tabular}{|r|l|}
\hline Surfaces & $\begin{array}{l}\text { total protection through disposable } \\
\text { cowers }\end{array}$ \\
\hline Surface & $\begin{array}{l}\text { total protection through disposable } \\
\text { cowers }\end{array}$ \\
\hline $\begin{array}{r}\text { Minimizing } \\
\text { aerosol } \\
\text { production }\end{array}$ & $\begin{array}{l}\text { surgical aspiration system } \\
\text { avoid when possible use of hand } \\
\text { pieces instruments } \\
\text { use of laser }\end{array}$ \\
\hline After dental treatment \\
\hline $\begin{array}{r}\text { Patient } \\
\text { discharge }\end{array}$ & $\begin{array}{l}\text { wear the mask immediately after } \\
\text { the treatment } \\
\text { the discharge } \\
\text { remove the shoe covers }\end{array}$ \\
\hline Ventilation & $\begin{array}{l}5-\text { min air change } \\
\text { Personal }\end{array}$ \\
disinfection of shield with 70 \% \\
protection & isopropyl alcohol \\
\hline Hand hygiene & $\begin{array}{l}\text { hand washing for at least } 60 \mathrm{~s} \text { and } \\
\text { then } 60 \% \text { hydroalcoholic solution } \\
\text { application }\end{array}$ \\
\hline
\end{tabular}

\section{DISCUSSION}

This study reports a descriptive analysis of clinical and dental characteristics of patients who accessed the Department of Oral Surgery of the University Dental Clinic in Albania, a public central institution responsible for covering the emergency dental care and oral treatment during COVID emergency outbreak. Preventive measures adopted during this special period were also described.

In Albania, routine dental services were suspended during the COVID-19 lockdown from 13 March to 11 May to reduce and control virus transmission. The WHO advises that routine non-essential oral health care, which usually includes oral health check-ups, dental cleanings and preventive care, can- be delayed until there has been sufficient reduction in COVID-19 transmission rates from community transmission to cluster cases or according to official recommendations at national, subnational or local level [14].

Regarding dental and oral pathologies, the Inflammatory diseases have the main incidence of in this study, similar to the findings of the literature $[15,16]$. As it is reported in literature certain instances such as dental trauma and progressive fascial space infection warrant emergency surgical intervention [17, 18, 19]. Intraoral X-ray exams were limited due to the stimulation of saliva production, preferring extra oral exams such as panoramic radiography [20, 21].
The main challenges in dental healthcare are the difficulty in the identification of the infected patient and the treatment of asymptomatic patient $[22,23,24,25]$. Ongoing surveillance is crucial to containing an epidemic. Surveillance includes screening, testing, tracking and monitoring the incidence of new cases [26, 27, 28, 29].

A study limitation was that the case identification of patients was not based on laboratory test but on pre-screening question declared by the patients and this is made difficult the real case identification. Moreover additional factors such as the incubation period, a possibly asymptomatic onset of the illness influence the accuracy of case identification. In order to decrease the risk to spread the infection, we took in consideration to identify the urgent need of the patient and focus on managing it with care, using clear and standardised preventive measurements. Also managing only one patient at a time, identifying compromised patients and applying short term appointments, using all the protective equipment for the operators, applying all the sterile preparations and disinfecting everything that could be in contact with the patient was very important. In this study even fearing the COVID-19 people had to seek surgical services when suffering from severe pain, swelling, bleeding or abscess.

\section{CONCLUSION}

The COVID-19 epidemic required an immediate re-organization of the local dental healthcare system. This paper described the two months' experience of the Albanian University School of Dentistry about the treatment of dental and oral pathologies into the development of infection prevention strategies during COVIID-19 pandemic. In order to decrease the possibility of contagion, it will be necessary to implement robust preventive measurements in the management of patients, operators and the environment. Recommendation proposed could help to improve the quality of assistance for patients with dental disorders and reduce the risk of infection in dental setting during the COVID-19 pandemic. In order to decrease the spread of the infection and for successful treatment it is important that the surgeon and every dentist abide by the recent recommendations of health authorities. After the first phase of response to COVID-19, public health measures will be reviewed and it is expected to expand and increase non- COVID19 urgent services. 


\section{CONFLICT OF INTEREST STATEMENT}

There are no potential conflicts of interest or any financial or personal relationships with other people or organizations that could inappropriately bias conduct and findings.

\section{REFERENCES}

[1] World Health Organization Official Website Rolling Updates on Coronavirus Disease (COVID-19). Updated 18 April 2020. (accessed on 20 April 2020); https://www.who.int/emergencies/diseases/nov el-coronavirus-2019/events-as-theyhappen?fbclid=IwAR2Kk1 KFnISKOTTnWdgEi3rCni0QmJyIo98PqwvlPGkq9kf23mR6D4wR4

[2] Wu F., Zhao S., Yu B., Chen Y.-M., Wang W., SongZ.-G., Hu Y., Tao Z.-W., Tian J.-H., Pei Y.-Y., et al. A new coronavirus associated with human respiratory disease in China. Natyre. 2020;579:265-269

[3] Ministero della Salute: COVID-19 Situazione nel Mondo. [(accessed on 23 April 2020)]; http://www.salute.gov.it/portale/nuovocoronavi rus/dettaglioContenutiNuovoCoronavirus.jsp?li ngua $=$ italiano\&id $=5338 \&$ area $=$ nuovoCoronavir us\&menu=vuoto

[4] Onder G, Rezza G, Brusaferro S. Case-Fatality Rate and Characteristics of Patients Dying in Relation to COVID-19 in Italy. JAMA. 2020 May 12;323(18):1775-1776

[5] Li R., Pei S., Chen B., Song Y., Zhang T., Yang W., Shaman J. Substantial undocumented infection facilitates the rapid dissemination of novel coronavirus (SARS-CoV2) Science. 2020;368:489-493

[6] Lu C.-W., Liu X.-F., Jia Z.-F. 2019-nCoV transmission through the ocular surface must not be ignored. Lancet. 2020;395:e39

[7] Belser J.A., Rota P.A., Tumpey T.M. Ocular tropism of respiratory viruses. Microbiol. Mol. Biol. Rev. 2013;77:144-156

[8] To K.K.-W., Tsang O.T.-Y., Yip C.C.-Y., Chan K.-H., Wu T.-C., Chan J.M.-C., Leung W.-S., Chik T.S.-H., Choi C.Y.-C., Kandamby D.H., et al. Consistent Detection of 2019 Novel Coronavirus in Saliva. Clin. Infect. Dis. 2020 doi: $10.1093 / \mathrm{cid} / \mathrm{ciaa} 149$

[9] Azzi L., Carcano G., Gianfagna F., Grossi P., Gasperina D.D., Genoni A., Fasano M., Sessa F., Tettamanti L., Carinci F., et al. Saliva Is A Reliable Tool To Detect SARS-CoV-2. J. Infect. 2020 doi: 10.1016/j.jinf.2020.04.005.

[10] Gamio L. The Workers Who Face the Greatest Coronavirus Risk. [(accessed on 20 April 2020)]; https://www.nytimes.com/interactive/ 2020/03/15/business/economy/coronavirus- worker-risk.html?action=click \&module= Top+Stories\&pgtype=Homepage

[11] Sabino-Silva R., Jardim A.C.G., Siqueira W.L. Coronavirus COVID-19 impacts to dentistry and potential salivary diagnosis. Clin. Oral Investig. 2020;24:1619-1621. doi: 10.1007/s00784-020-03248-X

[12] Spagnuolo G., De Vito D., Rengo S., Tatullo M. COVID-19 Outbreak: An Overview on Dentistry. Int. J. Environ. Res. Public Health. 2020;17:2094. doi: 10.3390/ijerph17062094

[13] Alharbi A., Alharbi S., Alqaidi S. Guidelines for dental care provision during the COVID-19 pandemic. Saudi Dent. J. 2020 doi: 10.1016/j.sdentj.2020.04.001

[14] American Dental Association Official Website What Constitutes a Dental Emergency? [(accessed on 20 April 2020)]; https://success.ada.org/ /media/CPS/Files/Ope n\%20Files/ ADA_COVID19_Dental_Emergency_DDS.pdf.

[15] American Dental Association ADA Interim Guidance for Management of Emergency and Urgent Dental Care. Updated 4/1/2020. [(accessed on 20 April 2020)]; https://www.ada.org/ /media/CPS/Files/ COVID/ADA_Int_Guidance_Mgmt_EmergUrg_Dental_COVID19?utm_source=adaorg \&u tm_medium $=$ VanityURL\&utm_content=interimguidanceflowcharts\&utm_campaign=covid-19.

[16] SIdP Società Italiana di Parodontologia e Implantologia COVID-19-Norme per L'attività Odontoiatrica. [(accessed on 20 April 2020)]; https://www.sidp.it/media/taxtbu3.pdf?fbclid= IwAR3 woxuY0a5aQ7EAuVGq0dyWfWElCiM dNCkEmCULCnLEA8-F4e41QvpNxZw.

[17] SIdP Società Italiana di Parodontologia e Implantologia COVID-19-Norme per L'attività Odontoiatrica. [(accessed on 20 April 2020)]; Available online: https://www.sidp.it/media/taxtbu3.pdf?fbclid= IwAR3woxuY0a5aQ7EAuVGq0dyWfWElCiM dNCkEmCULC Ministero della Salute Previeni le Infezioni con il Corretto Lavaggio Delle Mani. [(accessed on 20 April 2020)]; http://www.salute.gov.it/imgs/C_17_opuscoliP oster_340_allegato.pdf

[18] Peng X., Xu X., Li Y., Cheng L., Zhou X., Ren B. Transmission routes of 2019-nCoV and controls in dental practice. Int. J. Oral Sci. 2020;12:1-6. doi: 10.1038/s41368-020-0075-9.

[19] 3M Report Comparison of FFP2, KN95, and N95 and Other Filtering Facepiece Respirator Classes. Technical Bulletin, January, 2020, Revision 2. [(accessed on 20 April 2020)]; https://multimedia.3m.com/mws/media/179150 
0O/comparison-ffp2-kn95-n95-filteringfacepiece-respirator-classes-tb.pdf

[20] National Health Service Official Website COVID-19 Guidance and Standard Operating Procedure. Urgent Dental Care Systems in the Context of Coronavirus. Version 1. [(accessed on 20 April 2020)];2020 Apr 15; https://www.england.nhs.uk/coronavirus/wpcontent/uploads/sites/52/2020/04/C0282-covid19-urgent-dental-care-sop.pdf

[21] Fiche Pratique de Sécurité ED 105 Appareils de Protection Respiratoire et Métiers de la Santé. Inrs.fr. INRS. [(accessed on 20 April 2020)]; https://www.esstinrs.fr/3rb/ressources/ed105.pdf.

[22] Kirk-Bayley J., Combes J., Sunkaraneni S., Challacombe S. The Use of Povidone Iodine Nasal Spray and Mouthwash During the Current COVID-19 Pandemic May Reduce Cross Infection and Protect Healthcare Workers. Social Science Research Network; Rochester, NY, USA: 2020.

[23] Kariwa H., Fujii N., Takashima I. Inactivation of SARS coronavirus by means of povidoneiodine, physical conditions and chemical reagents. Dermatology (Basel) 2006;212(Suppl. 1):119-123

[24] Kirk-Bayley J., Combes J., Sunkaraneni S., Challacombe S. The Use of Povidone Iodine Nasal Spray and Mouthwash During the
Current COVID-19 Pandemic May Reduce Cross Infection and Protect Healthcare Workers. Social Science Research Network; Rochester, NY, USA: 2020

[25] Coronavirus disease 2019 (COVID-19) in the EU/EEA and the UK - tenth update https://www.ecdc.europa.eu/sites/default/files/d ocuments/RRA-COVID19-update10-2020-0611.pdf

[26] WHO Coronavirus Disease (COVID-19) Dashboard. https://covid19.who.int/

[27] Overview of Testing for SARS-CoV-2 (COVID-19) https://www.cdc.gov/coronavirus/2019ncov/hcp/testing-overview.html

[28] Chigurupati R, Panchal N, Henry AM, et al. Considerations for Oral and Maxillofacial Surgeons in COVID-19 Era: Can We Sustain the Solutions to Keep Our Patients and Healthcare Personnel Safe. J Oral Maxillofac Surg. 2020;78(8):1241-1256. doi:10.1016/j.joms.2020.05.027

https://www.ncbi.nlm.nih.gov/pmc/articles/ PMC7246053

[29] Considerations for the provision of essential oral health services in the context of COVID19: interim guidance, 3 August 2020. [(accessed on 20 April 2020)] https://www.who.int/publications/i/item/who2019-nCoV-oral-health-2020.1

Citation: Merita Bardhoshi, Edit Xhajanka, Eriselda Malushi, Dea Bardhoshi. Oral Surgery during Covid-19 Epidemic - Albanian Experience for Patient Management Attending Emergency Dental Services. ARC Journal of Dental Science. 2020; 5(2):22-29. DOI: https://doi.org/10.20431/2456-0030.0502005.

Copyright: () 2020 Authors. This is an open-access article distributed under the terms of the Creative Commons Attribution License, which permits unrestricted use, distribution, and reproduction in any medium, provided the original author and source are credited. 